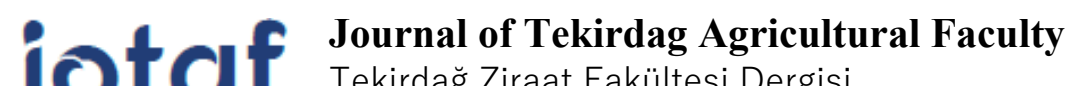 \\ Tekirdağ Ziraat Fakültesi Dergisi
}

\section{Tokat İlinde Kullanılan Bitki Koruma Makinelerinin Ürün Güvenliği Açısından Değerlendirilmesi}

Evaluation of Plant Protection Machines Used in Tokat Province in Point of Product Safety

\author{
Uğur TEMEL ${ }^{1}$, Yeşim Benal ÖZTEKİN ${ }^{1 *}$
}

\section{Özet}

Tarım, madencilik ve inşaat sektörleriyle birlikte en tehlikeli üç sektörden biri olarak kabul edilmektedir. Sektördeki iş sağlığı ve güvenliği sorunlarının iki temel nedeni tarım makineleri kazaları ve sektörde kullanılan kimyasallara maruz kalınmasıdır. Tarımsal üretimde bitki koruma uygulamalarında yaygın olarak kullanılan bitki koruma makineleri, kimyasal uygulamada kullanıldığı için her iki temel sorun için de özel bir öneme sahiptir. İş güvenliği çalışmaları çerçevesinde uzmanlar, iş sağlığı ve güvenliğini sağlamak için öncelikle güvenli makine / sistem bulunması ve ardından eğitim kavramını benimser. Bu durumda, çalışanlar tarafından kullanılan makine ve sistemlerin kabul edilen sağlı ve güvenlik gereksinimlerini karşılaması gerektiği söylenebilir. Ülkemizde yürürlükte olan mevzuat ve standartlar kapsamında tarımda bitki koruma uygulamalarında yaygın olarak kullanılan bitki koruma makinelerinin ürün güvenliği gereklilikleri belirlenmiştir. Bu çalışmada Tokat'ta kullanılan bitki koruma makinelerinin ürün güvenliği açısından değerlendirilmeleri amaçlanmıştır. Anketler Tokat ilini temsil eden Zile, Artova, Erbaa ve Niksar ilçelerinde bitki koruma makineleri kullanan çiftçilerle yüz yüze görüşülerek gerçekleştirilmiş ve kullandıkları bitki koruma makineleri incelenmiştir. Araştırma verileri SPSS paket programında istatistiksel analize tabi tutularak bulgular ortaya konulmuştur. Araştırma sonuçlarına göre, çiftçiler bitki koruma makinelerinin güvenli kullanımı hakkında yeterli bilgiye sahip olmayıp kullandıkları makinelerde güvenlik sorunları bulunmaktadır. Makinelere düzenli olarak ayar ve bakım yapılmamaktadır. Bitki koruma makinelerinin kalibrasyonu konusunda bilgi eksiklikleri olup çoğu çiftçi hiç yapmamaktadır. Bitki koruma makinesi ile traktör arasında kullanılan mafsallı millerin \% 78'inde muhafaza yoktur. Makinelerin yaklaşık yarısında temiz su deposu bulunmamaktadır. Hortumlar üzerinde maksimum çalışma basınçları yazılı olmayıp bunlar uygun bir muhafaza altında değildir. Sonuç olarak, makinelerin ürün güvenliği açısından sağlık ve güvenlik gereksinimlerini karşılaması için mevzuatlarla belirlenmiş önlemlerin alınması gerektiği söylenebilir.

Anahtar Kelimeler: Pülverizatör, Tarımda iş sağlığı ve güvenliği, Ürün güvenliği, Yeni yaklaşım, CE işareti

\begin{abstract}
Agriculture is considered one of the three most dangerous sectors, along with the mining and construction sectors. The two main causes of occupational health and safety problems in the sector are agricultural machinery accidents and exposure to chemicals used in the sector. Plant protection machines, which are used extensively in plant protection applications in agricultural production, have a special importance concerning both basic problems since

TSorumlu Yazar/Corresponding Author: Y eşım Benal Oztekın, Ondokuz Mayıs Unıversıtesı Zıraat Fakültesı Tarım Makınelerı ve Teknolojılerı Mühendısı̆gi Bölümü, 55139 Atakum/Samsun, Türkiye. E-mail: yurtlu@omu.edu.tr, (iD OrcID: 0000-0003-2387-2322

${ }^{1}$ Uğur Temel E-mail: ugur_temel_1990@hotmail.com (D) OrcID: 0000-0002-8856-338X

Atıf/Citation: Temel, U., Öztekin, Y.B. Tokat İlinde Kullanılan Bitki Koruma Makinelerinin Ürün Güvenliği Açısından Değerlendirilmesi. Tekirdağ Ziraat Fakültesi Dergisi, 17(3), 276-284.

*Bu çalışma Yüksek Lisans tezinden özetlenmiştir.

(CBu çalışma Tekirdağ Namık Kemal Üniversitesi tarafından Creative Commons Lisansı (https://creativecommons.org/licenses/by-nc/4.0/)

kapsamında yayınlanmıştır. Tekirdağ 2019
\end{abstract}


they are used in chemical application. Within the framework of occupational safety studies, experts adopt the concept of safe machinery / system and then education in order to ensure occupational health and safety. In this case, it can be said that the machines and systems used by employees must meet the accepted health and safety requirements. Product safety requirements of plant protection machines commonly used in plant protection applications in agriculture have been determined within the scope of the regulations and standards in force in our country. In this study, it is aimed to evaluate the plant protection machines used in Tokat in terms of product safety. Surveys were conducted through face-to-face interviews with farmers using plant protection machines in Zile, Artova, Erbaa and Niksar districts representing Tokat province and the plant protection machines they used were examined. According to the results of the research, farmers do not have enough information about the safe use of plant protection machines and there are safety problems in the machines they use. The machines are not adjustment and maintained regularly. There is no protection in $78 \%$ of the shafts used between the plant protection machine and the tractor. There is no clean water tank in about half of the machines. The maximum operating pressures are not written on the pressure hoses and are not in a housing. Necessary measures should be taken to ensure that the machines meet the health and safety requirements for product safety.

Keywords: Sprayer, Health and safety in agriculture, Product safety, New approach, CE marking 


\section{Giriş}

Tarım bugün, gelişmiş ülkeler de dâhil olmak üzere birçok ülkede en tehlikeli sektörden biridir. Tarım işlerindeki sağlık ve güvenlik uygulamalarını diğer işlerden ayıran temel özellikler; iş yeri ve yaşam alanının aynı yerde olması ve genellikle tüm aile üyelerinin iş ile iç içe yaşaması ve çalışması, tarımsal üretim yapılan alanların küçüklüğü nedeniyle kısa süreler için oluşturulan sağlıksız yaşam koşulları, tarımsal üretimin mevsimlik olması ve belirli işlerin birbiri ardına kısa sürede yapılması nedeniyle çalışanların kayıt dışı olması, yoğun mevsimlik işgücü gerektirmesi ve işgücünün sürekli yer değiştirmesi, işlerin büyük çoğunluğunun açık alanlarda yapılma zorunluluğu, kimyasal kullanımının kontrolsüz artışı ve pestisit satış ve uygulamasının yeterince denetlenememesi, tarımda iş sağlığı ve güvenliği standart ve yönetmeliklerinin olmayışı ya da uygulama güçlükleri, çalışanların eğitim düzeyinin düşüklüğüne bağlı sağlık ve güvenlikleri üzerinde kontrollerinin yetersizliği, çalışanların iş sağlığı ve güvenliği konularında bilgilendirilmemiş olması vb. şeklinde sıralanabilir (Yurtlu ve ark., 2015).

Ülkemizde tarımsal üretimde ürün kaybının önüne geçilmesi için uygulanan bitki koruma faaliyetlerinin büyük bir kısmı bitki koruma makineleri kullanılarak yapılan kimyasal mücadele şeklinde olmaktadır. Bu makineler kimyasal mücadele ilaçlarını tekdüze olarak bitkilere veya toprağa dağıtmakta ve böylece etkili bir mücadeleyi mümkün kılmaktadır. Tarımsal mücadelede kullanılan pülverizatörlerin özellikleri, pestisitlerin etkilerini sınırlamak, tarımsal mücadelenin etkin bir şekilde yürütülmesini ve kimyasalın hedef bitkiye doğru bir şekilde ulaşmasını sağlamak açısından önemlidir.

Bitki koruma makineleri, hem bir tarım makinesi olarak kazalara sebebiyet vermesi açısından hem de kimyasal uygulamada kullanılan bir makine olması nedeniyle, etkili tarımsal savaş yapılmasındaki öneminin yanı sıra, operatörlerin sağllk ve güvenliği, çevresel etkiler ve gıda güvenliği gibi çok yönlü önem ve etkileri olan makinelerdir. Bitki koruma amacıyla pestisit uygulanmasında kullanılan makineler, kimyasal ürünlerin uygulanmasında kullanıldığından operatör için mekanik tehlikeleri barındırmakla birlikte diğer canlılar ve çevre açısından kimyasal bulaşması, zehirlenmeler, meslek hastalıkları, çevre kirliliği vb birtakım sorunları da bünyesinde barındırmaktadır. Bu sorunların sebepleri kullanım alışkanlıkları, makinenin ayar ve bakımlarının doğru bir şekilde yapılmaması, pestisit kullanımında yanlış uygulamalar, kişisel koruyucu donanım kullanmama, talimat el kitabının okunmaması, kullanıcıların eğitim ve bilgi eksikliği vb şeklinde açıklanabilir.

İş güvenliği çalışmaları çerçevesinde konu ile ilgili çalışanların üzerinde anlaşmaya vardığı en önemli nokta "önce güvenli makine/tasarım/imalat sonra eğitim" anlayışıdır. Bu nedenle tarımda çalışanlar tarafından kullanılacak her türlü ürün/makine/sistemin kabul görmüş güvenlik standartları içerisinde tasarlanması ve üretilmesi sağlanmalıdır (Yurtlu ve ark., 2010).

Ülkemizdeki bitki koruma makinelerinin imalatı, piyasaya sürülmesi ve kullanımı konularını kapsayan iki yaklaşım bulunmaktadır. Bunlardan biri tüketicinin kullanımına sunulan ürünlerin taşıması gereken asgari sağlık ve güvenlik gereksinimleri yaklaşımı olarak özetlenebilecek ürün güvenliği yaklaşımı, diğeri Zirai Mücadele Alet ve Makineleri Yönetmeliği ile ilgili uygulamalardır. Piyasada bulunan tarım makinelerinin temel sağlık ve güvenlik gereksinimlerini karşılaması ve tarımda güvenli çalışma koşullarının temellerinden biri olan güvenli ürün koşulunun sağlanması açısından yürürlükte olan 2006/42/AT Makine Emniyeti Yönetmeliği'nin tam olarak uygulanması büyük önem taşımaktadır (Anonim, 2019). 2006/42/AT Makine Emniyet Yönetmeliği'nin amacı; makinelerin usulüne uygun şekilde kullanıldığında, bakımı yapıldığında ve amaçlar doğrultusunda kullanıldığında, insan sağlığına, güvenliğine, çevre ve canlılara zarar vermiyorsa piyasaya arz edilmelerini, tasarım ve imalat aşamasında uyulması gereken temel emniyet şartları ile takip edilmesi gereken uygunluk değerlendirme prosedürlerini ve uygunluk değerlendirmesi yapacak onaylanmış kuruluşların görevlendirilmesinde dikkate alınacak asgari kriterleri düzenlemektir. 2006/42/AT Makine Emniyet Yönetmeliği’ne ek olarak 02.04.2011 tarih ve 27893 sayılı Resmi Gazete 'de "Makine Emniyet Yönetmeliği (2006/42/AT)'nde Değişiklik Yapılmasına Dair Yönetmelik" yayınlanarak bu yönetmelikte Bitki Koruma Makineleri için ilave sağlık ve güvenlik gereksinimlerinin neler olduğu tanımlanmıştır. Bu yönetmelikte, Madde 11'de belirtildiği şekilde Ek-1'in "Belirli makina kategorileri için ilave sağlık ve güvenlik gerekleri" başlıklı 2 numaralı paragrafı aşağıdaki şekilde değiştirilmiş ve bu paragrafa 2.3 numaralı paragraftan sonra gelmek üzere 2.4 numaralı paragraf eklenmiştir. Ülkemizde bitki koruma makinelerinin imalatı ve satışı ile ilgili olarak Tarım ve Ormancıllk Bakanlığı, Gıda ve Kontrol Genel Müdürlüğü tarafindan uygulaması yürütülen özel bir yönetmelik mevcuttur. Bu yönetmelik "Zirai Mücadele Alet ve Makineleri Hakkında Yönetmelik" adı ile 02.04.2011 tarih ve 27893 sayılı Resmi Gazete 'de 
yayınlanarak yürürlüğe girmiştir (Anonim, 2011). Bu yönetmeliğin amacı, sağlıklı ve güvenilir bitkisel üretimin yapılması, insan sağlı̆̆ı ve çevreye duyarlı mücadele yöntemlerinin geliştirilmesi için entegre mücadele programlarının ve uygulama projelerinin hazırlanması, yürütülmesi ve yaygınlaştııılmasıdır. Bu yönetmelik; tüm zirai alet ve makinelerinin onayı, imalatı, ruhsatlandırılması, bayiliklerin görev ve sorumlulukları, piyasaya arzı ve denetimleri ile ilgili usul ve esasları kapsar. Bakanlıkça onaylı bitki koruma alet ve makineleri, imal izin belgesi, ruhsat alınması ve deney testleri yapılması koşullarından sonra piyasaya sunulabilir. Piyasaya sunulan bitki koruma makinesinin satışları bayilik izin belgesi almış gerçek ve tüzel kişiler tarafından yapılır. Bitki koruma makinesinin imalatçısı veya yetkili temsilcisi, risk değerlendirmesi ve azaltılması sürecine uygun olarak pestisitlerin istemsiz çevreye yayılımı ile ilgili bir değerlendirmenin yapılmasını sağlamalıdır. Bitki koruma makineleri, yukarıda bahsedilen risk değerlendirmesinin sonuçları düşünülerek tasarlanmalı ve yapılmalıdır. $\mathrm{Bu}$ sayede makine, çevreye istem dışı pestisit püskürtülmeksizin çalıştırılabilir, ayarlanabilir ve bakımı yapılabilir.

Demir (2005), çalışmasında Tekirdağ ili ve çevresinde yer alan tarımsal işletmelerin, ilaçlama makineleri açısından mekanizasyon durumu, makineler ile ilgili sorunları ve bu makinelerin bakım, onarım, satın alma vb. ihtiyaçlarını nasıl belirlediklerini saptamayı amaçlamıştır. Bu amaçla çiftçilerle anketler yapılmış, bu doğrultuda sorunlar tespit edilmeye çalışılmıştır. Anket sonuçlarına göre, çiftçilerin makinelerin bakım ve ayarlarına dikkat etmedikleri, eksikliklerini giderebilmek için ilgili kuruluşların eğitim seminerleri vermeleri durumunda bunlara katılmak istediklerini belirttiklerini ortaya koymuştur. Yurtlu ve ark. (2008) yaptıkları araştırmada, Türkiye'de imal edilerek piyasaya sunulan bitki koruma makinelerini ürün güvenliği açısından değerlendirmeye çalışmışlardır. $\mathrm{Bu}$ amaçla ilgili yönetmelik kapsamında uygulamada olan TS EN 907 ürün güvenliği standardına göre bir kontrol listesi oluşturarak inceledikleri 35 makine üzerinde değerlendirmeler yapmışlardır. Araştırma sonucunda, piyasaya sunulan makinelerde zayıf ve güçlü yönleri tespit ederek imalatçılara yol gösterici değerlendirmeler yapmaya çalışmışlardır. Velioğlu (2016), yaptığı çalışmada, makinelerin 2006/42/AT Makine Emniyeti Yönetmeliği'ne uygunluklarını belirlemeye yönelik olarak "Makine Uygunluk/Risk Değerlendirmesinin" bilgisayar programı yardımıyla yapılmasını amaçlamıştır. Araştırmacı "Makine Risk İndeksi” adı verilen bir yaklaşım geliştirerek makine üzerinde bulunan risklerin puanlaması, derecelendirilmesi ve azaltılmasını hedeflemiştir. Bu amaçla geliştirdiği bir modelle uygunsuzlukları sayısallaştırmış ve bu modeli esas alan web tabanlı bir program geliştirmiştir. Sisteme girilen bilgilerin işlenmesi sonucu program tarafından bir düzenleme listesi oluşturulmakta, imalatçıların bu kurala uyarak makinelerini mevzuata uygun bir şekilde üreterek "güvenli makine" hedefine ulaşması amaçlanmaktadır.

Bitki koruma uygulamalarında yoğun olarak kullanılan makinelerin yürürlükte olan yönetmelikler kapsamında ürün güvenliği gereksinimlerini karşılamaları, bu uygulamalarda iş güvenliğini tesis edebilmenin ilk şartıdır. $\mathrm{Bu}$ araştırmanın amacı, pilot bir il olarak belirlenen Tokat İlinde kullanılan bitki koruma makinelerinin güvenlik durumlarını inceleyerek iş güvenliği açısından bir değerlendirme yapmaktır.

\section{Materyal ve Metot}

Araştırma materyalini, pilot il olarak seçilen Tokat ili Zile, Artova, Erbaa ve Niksar ilçelerinde çiftçilerden anket yoluyla elde edilen bilgiler, bu çiftçilerin kullandıkları bitki koruma makineleri üzerinde yapılan incelemeler ve araştırma bölgesinde yapılan gözlemler oluşturmaktadır. Anketler ve incelemeler, 2016 yılı Mart, Nisan ve Haziran aylarında yapılmıştır. Anket çalışması yapılacak ilçeler belirlenirken, bitki koruma makinelerinin yoğun olarak kullanılma durumu ve Tarım ve Ormancılık Bakanlığı Çiftçi Kayıt Sistemi (ÇKS) verileri referans alınmıştır. $\mathrm{Bu}$ araştırmada anket verilerinin elde edilmesinde Tokat İlini temsil eden, bitki koruma makinelerinin yoğun olarak kullanıldığı Zile, Artova, Erbaa ve Niksar ilçeleri seçilmiştir. Örnek büyüklüğü belirlenirken ÇKS verilerinden yola çıkılarak 4 ilçedeki çiftçilerden araştırmada hata payı $\% 5$ olarak kabul edilerek $\% 95$ güven derecesinde 164 adet örnek sayısı tesadüfi örnekleme yöntemi ile belirlenmiştir. Optimum örnek hacmi hesaplamasında aşağıda yer alan Eşitlik 1 kullanılmıştır (Yamane, 1967):

$$
n=\frac{N \sum N_{h} S_{h}^{2}}{N^{2} D^{2}+\sum N_{h} S_{h}^{2}}
$$

Eşitlikte; n: anket yapılacak işletme sayısını, N: ana kitlede bulunan işletme sayısını, $\mathrm{N}_{\mathrm{h}}$ : her bir tabakadaki işletme sayısını, $\mathrm{S}_{\mathrm{h}}$ : her bir tabakadaki standart sapmayı ve D: araştırmada izin verilen hata payını ifade etmektedir. 
Tokat ilinde kullanılan bitki koruma makinelerinin ürün güvenliği açısından değerlendirilmesi

Yapılan anketlerin ilçelere göre dağılımı ve yüzdeleri, Tablo 1'de yer almakta olup ÇKS verilerindeki çiftçi sayılarına göre hazırlanmıştır.

Tablo 1. Anket yapılan ilçeler ve anketlerin sayısal dă̆glımı

Table 1. Districts surveyed and numerical distribution of surveys

\begin{tabular}{ccc}
\hline İlçeler & $\begin{array}{c}\text { Anket Sayısı } \\
\text { (Adet) }\end{array}$ & Dağılım (\%) \\
\hline Zile & 53 & 32.3 \\
Erbaa & 46 & 28.0 \\
Niksar & 38 & 23.2 \\
Artova & 27 & 16.5 \\
\hline Toplam & 164 & 100 \\
\hline
\end{tabular}

Anket soruları, çiftçilerin kullandıkları bitki koruma makineleri ile ilgili bilgi almak ve ürün güvenliği açısından durumlarını belirlemek amacıyla geliştirilmiştir. Bu amaçla 2006/47/Makine Emniyet Yönetmeliği ve TS EN ISO 4254-6:2010 Tarım Makinaları-Güvenlik-Bölüm 6: Pülverizatörler ve sıvı gübre dağıtıcıları standardı gereksinimleri göz önüne alınmıştır (Anonim, 2010). Anket formlarının işlenebilirliğinin test edilmesi için önce pilot çalışma uygulanmış, bazı sorular araştırmaya uygun olmadığı düşünülerek anket formundan çıkartılmış ve araştırmaya uygun olduğu varsayılan sorular ise anket formuna eklenmiştir. Anketler, araştırmacılar tarafindan bitki koruma makinesi kullanan çiftçilerle birebir görüşmeler yoluyla ve kullandıkları makineler incelenerek yürütülmüştür. Anket yapılırken, görüşülen kişilere anlaşılmayı pekiştirmek için bazı sorular açıklanmış, böylece soruların yanlış anlaşılma durumu ortadan kaldırılarak elde edilen verilerin güvenilirliği ve doğruluğu arttırılmaya çalışılmıştır. Anket çalışması için görüşme yapılan çiftçiler Zile, Artova, Erbaa ve Niksar ilçelerinde bitki koruma makinesi kullanan çiftçilerden tesadüfi olarak belirlenmiştir. Anket formlarında yer alan veriler SPSS paket programında analiz edilmiştir.

\section{Araştırma Sonuçları ve Tartışma}

\subsection{Bitki Koruma Makineleri ile İlgili Bilgiler}

Çiftçilerin kullandıkları bitki koruma makinesi türü, temin etme yolları, kullanma sıklığı vb konulara ilişkin durumlarına ait veriler Tablo 2' de yer almaktadır.

Tablo 2. Bitki koruma makinelerine ait bilgiler

Table 2. Information on plant protection machines

\begin{tabular}{|c|c|c|c|}
\hline & & $\begin{array}{r}\text { Kişi } \\
\text { Sayısı } \\
\end{array}$ & Dağılım (\%) \\
\hline \multirow{7}{*}{$\begin{array}{l}\text { Bitki koruma } \\
\text { ürünlerini uygularken } \\
\text { kullanılan makine }\end{array}$} & Tarla pülverizatörleri & 164 & 100 \\
\hline & Bahçe pülverizatörleri & 0 & 0 \\
\hline & Bağ pülverizatörü & 0 & 0 \\
\hline & Sırt pülverizatörü & 0 & 0 \\
\hline & Elle çalıştırılan sırt pülverizatörü & 0 & 0 \\
\hline & Tohum ilaçlama makinesi & 0 & 0 \\
\hline & Kendi yürür pülverizatör & & \\
\hline \multirow{6}{*}{ Makineleri temin etme yolları } & Kendime ait & 164 & 100 \\
\hline & Komşumdan alıyorum & 0 & 0 \\
\hline & Kiraliyorum & 0 & 0 \\
\hline & Kooperatiften kiralıyorum & 0 & 0 \\
\hline & Ortak kullanıyorum & 0 & 0 \\
\hline & Diğer & 0 & 0 \\
\hline
\end{tabular}


JOTAF/ Journal of Tekirdag Agricultural Faculty, 2020, 17(3)

\begin{tabular}{llcc}
\hline & Kendi tecrübelerimle yaparım & 62 & 37.8 \\
Arıza, tamir ve bakım & İmalatçı ya da satış bayiine danışııı & 11 & 6.7 \\
ihtiyacında başvurulan yer & Talimat el kitabına uyarım Komşulara & 10 & 1.2 \\
& sorarım & 2 & 1.2 \\
& Diğer (sanayide tamirci) & 79 & 48.2 \\
\hline & Ayda bir & 0 & 0 \\
Bitki koruma & 3 ayda bir & 2 & 1.2 \\
makinesini & Tarlanın durumuna göre her & 141 & 86.0 \\
kullanma sıklığı & zaman Ziraat mühendisine & 21 & 12.8 \\
& danışarak & 0 & 0 \\
\hline & Diğer & 27 & 16.5 \\
& Fiyat uygunluğu & 14 & 8.5 \\
& Kredi imkânının sağlanması & 28.0 \\
Makineyi & Sağlamlık ve dayanıklılık faktörü & 46 & 7.3 \\
satın alırken & Depo kapasitesi & 12 & 14.0 \\
dikkät edilen & Yedek parça bulma kolaylı̆̆ı & 23 & 22.0 \\
faktörler & Tamir ve bakım kolaylığ 1 & 36 & \\
& & & 3.7 \\
& Komşu tavsiyesi & 6 & 0 \\
& Rengine göre & 0 & 0 \\
\hline
\end{tabular}

Çiftçilerin tamamı bitki koruma ürünlerini uygularken tarla pülverizatörleri kullanmakta olup makineler kendine aittir. Makine ile ilgili arıza, tamir ve bakım ihtiyacında çiftçilerin yaklaşık \%38'ikendi tecrübelerine göre bir çözüm yolu üretmektedir. Çiftçiler makineleri üretim desenlerine göre ihtiyaç olduğu her zaman, sıklıkla kullanmaktadır. Çiftçiler bitki koruma makinesini satın alırken sağlamlık ve dayanıklılık faktörü ile tamir ve bakım kolaylığını öncelikli olarak tercih nedeni olarak ifade etmişlerdir.

Bitki koruma makinelerinin kullanımı sırasında çiftçilerin karşılaştığı sorunlar ve son bir yılda karşılaşma sıklıkları incelendiğinde, bitki koruma makinelerinin kullanımı sırasında \%69 oranında memelerde tıkanma, aşınma, akma vb problemlerle karşılaşılmaktadır. Bu durumun sebebinin, memeler ile ilgili temizlik ve değiştirme işlemlerini zamanında ve doğru olarak yapmamaları olduğu tahmin edilmektedir. Nitekim, ikinci derecede karşılaşılan sorunlarını \%25 ile bilinçsiz kullanım, temizlik, bakım vb işlemleri ihmal ya da geciktirme olarak ifade etmişlerdir.

\subsection{Bitki Koruma Makinelerinin Ürün Güvenliği Açısından Durumu}

Bitki koruma makinelerinin ürün güvenliği açısından durumları ile ilgili bilgiler Tablo 3'de yer almaktadır.

Tablo 3. Bitki koruma makinelerinin ürün güvenliği açısından durumları Table 3. Plant protection machines status in terms of product safety

\begin{tabular}{llcc}
\hline Makinelere ait bilgiler & & Kişi sayısı & Yüzde (\%) \\
\hline & Çok iyi & 4 & 2.4 \\
& Yeterli & 36 & 22.0 \\
Makinedeki güvenlik aksamları & Orta & 121 & 73.8 \\
ve donanımları & Çok Kötü & 3 & 1.8 \\
& Evet & 0 & 0 \\
\hline \multirow{3}{*}{ Mafsallı mil muhafazası } & Hayır & 36 & 22.0 \\
& & 128 & 78.0 \\
\hline \multirow{2}{*}{ Hareketli mil muhafaza } & Evet & 17 & 10.4 \\
& Hayır & 147 & 89.6 \\
\hline Basınç göstergesi & Evet & 161 & 98.2 \\
& Hayır & 3 & 1.8 \\
\hline
\end{tabular}


Tokat ilinde kullanılan bitki koruma makinelerinin ürün güvenliği açısından değerlendirilmesi

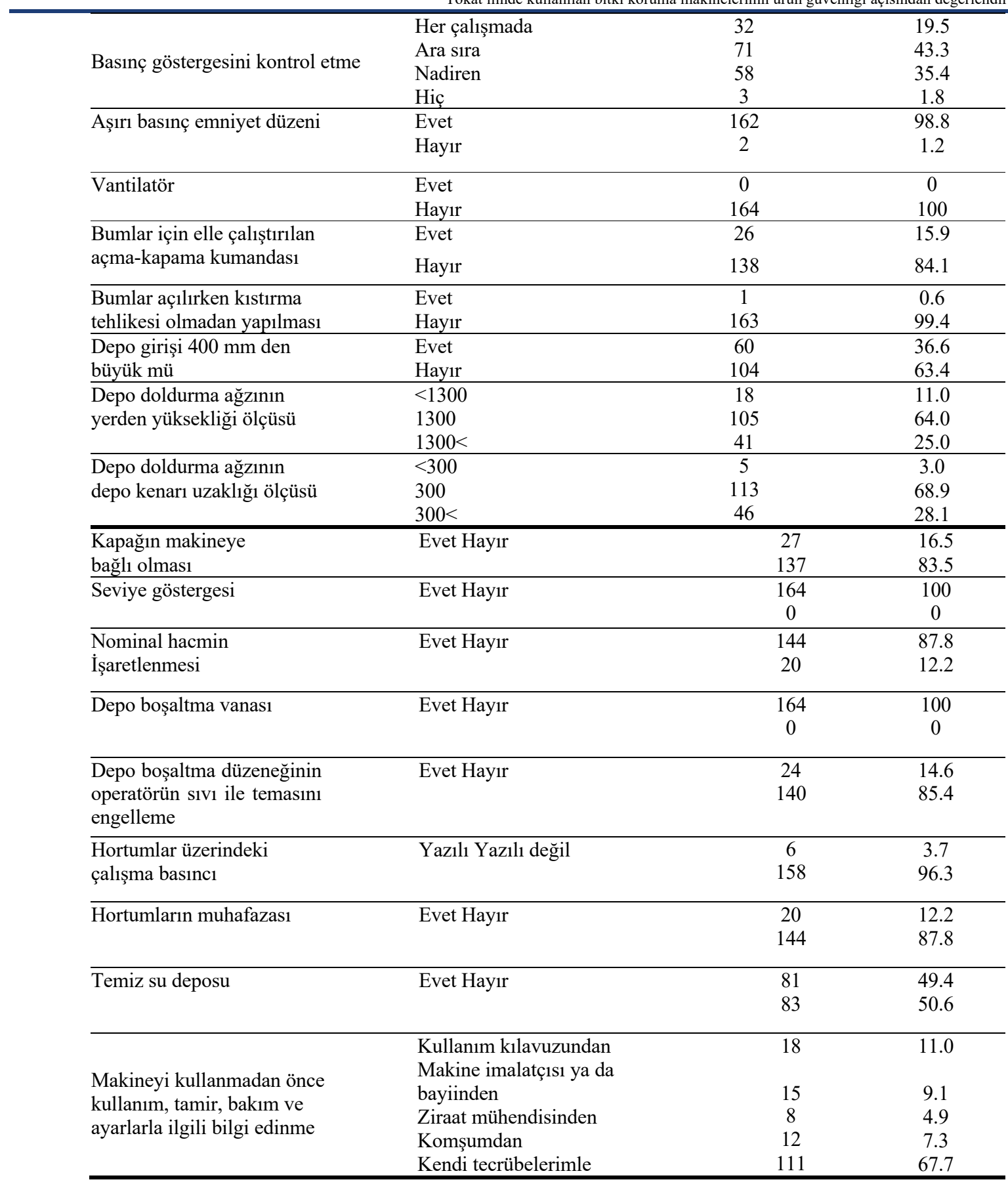

Çiftçilere makinedeki güvenlik aksamları ve donanımları hakkındaki bilgileri sorulduğunda çiftçilerin yaklaşık \%74'ü orta düzeyde bilgi sahibi olduklarını ifade etmişlerdir. Çiftçilerin yaklaşık \%10'u ziraat mühendisinden, \%1'i ziraat odası ve çiftçi birliğinden, \%12'si il ve ilçe tarım müdürlüğünden, \%6'sı imalatçı ve satış bayiinden, \%3'i komşu çiftçilerden ve $\% 5$ ' u kullanım kılavuzundan makinenin güvenlik aksamları ve donanımları ile ilgili bilgi edindiklerini belirtirken $\% 63$ 'i hiçbir yere danışmayıp kendi tecrübelerini kullandıklarını belirtmişlerdir. Çiftçilerin kullandıkları bitki koruma makinelerinin, \%78'inde mafsallı mil muhafazası, \%90‘ında ise makine üzerindeki hareketli miller üzerinde muhafaza bulunmamaktadır. Makinelerin basınç göstergesi \%98'sinde bulunmakla birlikte göstergelerin kontrol durumu zayıftır. Bumlar için açma kapama düzeninin makinelerin \%84'ünde olmadığı görülmüsşür. Bumlar elle açılırken makinelerin tamamında kıstırma tehlikesi olmaktadır. Çiftçilerin elinde bulunan makinelerin \%84'ünde depo kapağı makineye bağlı değildir. İncelenen makinelerin tamamında seviye göstergesi vardır. Makinelerin \%88'inde nominal hacim işaretli iken \%12'sinde işaretli değildir. Depo boşaltma vanası makinelerin tamamında vardır. Ancak incelenen bitki 
koruma makinelerinin \%85'inde depo boşaltma düzeneği operatörün sıvı ile temasını engelleyecek şekilde değildir. Makinelerin \%97'sinde hortumlar üzerinde en fazla çalışma basıncı yazılı değildir ve \%88'inde hortum muhafazaları bulunmamaktadır. Makinelerde \%51 oranında temiz su deposu yoktur. Çiftçilerin makineyi kullanıma hazırlama aşamasında kullanmadan önce kullanım, tamir, bakım ve ayarlarla ilgili bilgileri \%11'i kullanım kılavuzundan, \%9'u makine imalatçısı ve satı̧ bayiinden, \%5'i ziraat mühendisinden, \%7'si komşulardan yardım alarak yaparken, \%68' i kimsenin yardımını almadan kendi bilgi ve becerileri ile yaptıklarını belirtmişlerdir. Bitki koruma makinelerinin ürün güvenliği açısından irdelendiği bu çalışmada çiftçilerin kullandığ 1 bitki koruma makinelerinin ürün güvenliği, makinenin üzerindeki güvenlik aksamları ve muhafazalar açısından yeterli düzeyde olmadıkları görülmektedir. Çiftçilere güvenli kullanım ve ürün güvenliği ile ilgili yeterli seviyede bilgi aktarımı söz konusu değildir.

\section{Sonuc}

Tokat ilinde çiftçilerin yoğun olarak kullandığı bitki koruma makinelerinin ürün güvenliği durumunun incelendiği bu çalışmada aşağıda yer alan belirlemeler yapilmıştır:

- Bitki koruma makinesi kullanan çiftçilerin ürün güvenliği hakkında yeterli düzeyde bilgi sahibi değildirler.

- Bitki koruma makinelerinin \%78'inin mafsallı mil muhafazası yoktur.

- Basınç göstergeleri bulunmakla birlikte göstergelerin doğruluğu kontrol edilmemektedir.

- Bitki koruma makinelerinin \%51 'inde temiz su deposu bulunmamaktadır.

- Basınçlı sıvı taşıyan hortumlar üzerinde en yüksek çalışma basınçları yazılı olmayıp bu hortumlar muhafaza içine alınmamıştır.

- Çiftçilerin kullanma bilgileri konusunda destek almamaktadırlar.

Yapılan bu araştırma ile çiftçilerin kullandıkları makinelerde ürün güvenliği sorunları bulunduğu belirlenmiştir. Bitki koruma makinelerinin iş güvenliği kuralları çerçevesinde kullanılabilmesi için öncelikle makinelerin imalatçı tarafindan güvenli olarak imal edilmesi gerekmektedir. Bunun için öncelikle makinelerin imalat ve piyasaya arz aşamasında kontrol ve denetlemelerinin uygun bir şekilde yapılması sağlanmalıdır. Böylece bu makineler güvenli olarak çiftçilerin kullanımına sunulabilir. Makinelerin bu şekilde kullanıma sunulmasının ardından, makineleri kullanacak çiftçiler için eğitim çalışmaları yürütülerek bu makinelerin güvenli bir şekilde kullanılmaları sağlanmalıdır.

\section{Teșekkür}

Bu çalışma Ondokuz Mayıs Üniversitesi Bilimsel Araştırma Projeleri kapsamında PYO.ZRT.1904.15.008 numaralı proje ile desteklenmiştir. 


\section{Kaynakca}

Anonim (2019). 2006/42/AT Makine Emniyet Yönetmeliği. 03.03.2009 Tarih ve 27158 Sayılı Resmi Gazete. http://www.resmigazete. gov.tr. (erişim tarihi: 01.10.2019).

Anonim (2011). Zirai Mücadele Alet Makineleri Hakkında Yönetmelik. 02.04.2011 Tarih ve 27893 Sayılı Resmi Gazete.

Anonim (2010). Türk Standardı. TS EN ISO 4254-6:2010 Tarım Makinaları-Güvenlik-Bölüm 6: Pülverizatörler ve sıvı gübre dağıtıcıları. TSE, Ankara.

Demir, C. (2005). Tekirdă̆ ili tarım işletmelerinde kimyasal savaşımda kullanılan bitki koruma makinelerinin teknik özellikleri ve uygulama sorunlarının saptanması üzerine bir araştırma. (Yüksek Lisans Tezi) Namık Kemal Üniversitesi Fen Bilimleri Enstitüsü, Tekirdağ.

Velioğlu, H. (2016). Tarım Makinelerine Yönelik Bir Risk Değerlendirme Yöntemi Geliştirilmesi ve Web Tabanlı Uygulaması. (Doktora Tezi) Ankara Üniversitesi Fen Bilimleri Enstitüsü, Ankara.

Yamane, T. (1967). Elemantary Sampling Theory. Printice Hall Incorporated, Englewood Cliffs, New Jersey, USA.

Yurtlu, Y.B., Koçtürk, B.Ö., Serim, A.T. (2008). Determination of safety level of some sprayers manufactured in Turkey, Proceedings, pp. 265-270, 14-17 October, 10th International Congress on Mechanization and Energy in Agriculture Antalya, Türkiye.

Yurtlu, Y.B., Ekmekci, K., Gölbaşı, M., Yeşiloğlu, E. (2010). Safer agriculture for employees in rural. Tarım Makineleri Bilimi Dergisi, 6 (1), 1-4.

Yurtlu, Y.B., Öz, E., Alayunt, F.N., Çakmak, B., Şimşek, Z. (2015). Tarımda İş Güvenliği ve Sağlığı. Türkiye Ziraat Mühendisliği VIII. Teknik Kongresi, Bildiriler Kitabı 2, 1435-1454, 12-16 Ocak, Ankara. 